\title{
PERENCANAAN JALUR SEPEDA YANG TERINTEGRASI DI KOTA BEKASI
}

\author{
Khusnul Khotimah, MT \\ Dosen STTD \\ Jl. Raya Setu No.89, Bekasi \\ Telp./fax. 0218254640 \\ Bobby Agung Hermawan, MT \\ Dosen STTD \\ Jl. Raya Setu No.89, Bekasi \\ Telp./fax. 0218254640
}

\author{
Sudirman Anggada, MT \\ Dosen STTD \\ Jl. Raya Setu No.89, Bekasi \\ Telp./fax. 0218254640
Made Arka Hermawan, MT
Dosen STTD
J1. Raya Setu No.89, Bekasi \\ Telp./fax. 0218254640
}

\begin{abstract}
Research on "Humanist and Integrated Bicycle Path Planning in Bekasi City Center" is intended as an input in the formulation of a bicycle / road development policy to support environmentally friendly transportation programs and support policy making in the implementation of integrated public transport in the Bekasi region. Data collection in planning Humanistic and Integrated Bicycle Paths includes prefernsi bicycle use surveys, geometric surveys and road equipment, traffic characteristics surveys. In the data analysis technique, respondents' characteristics, parking space design, and parking management were obtained in the STTD environment.

From the analysis of the bicycle lane corridor recommended in the city of Bekasi with the concept of interconnection between trip generation in this case the residential area with the travel attraction area, namely the train station and commercial areas. The 3 (three) bicycle lane corridors are Prima HarapanStation Bekasi Housing with the Struggle Highway Route which consists of 3 (three) road segments; Housing Kemang Pratama-Summarecon Bekasi with South Boulevar Road Route, Jl. Boulevar Ahmad Yani, Jl. Ahmad Yani, and Jalan Raya Pekayon; Wisma Jaya Housing - Bekasi Station with the route Highway Struggle, Agus Salim Road, and Mekarsari Road.
\end{abstract}

Keywords: Bike Paths, Bike Path Routes, Bike Path Integration 


\section{ABSTRAKSI}

Penelitian "Perencanaan Jalur Sepeda yang Humanis dan Terintegrasi di Pusat Kota Bekasi" dimaksudkan sebagai bahan masukan dalam perumusan kebijakan pembangunan jalur sepedal guna mendukung program transportasi yang ramah lingkungan serta mendukung pengambilan kebijakan dalam penyelenggaraan angkutan umum terintegrasi di wilayah Bekasi.

Pengumpulan data dalam perencanaan Jalur Sepeda Yang Humanis dan Terintegrasi meliputi survei prefernsi penggunaan sepeda, survei geometric dan perlengkapan jalan, survei karakteristk lalu lintas. Dalam teknik analisa data diperoleh karakteristik responden, desain ruang parkir, dan manajemen parkir di Lingkungan STTD.

Dari hasil analisis koridor jalur sepedayang direkomendasikan di Kota Bekasi dengan konsep keterhubungan antar bangkitan perjalanan dalam hal ini area pemukiman dengan area tarikan perjalanan yaitu simpul transportasi stasiun kereta maupun area komersil. 3 (tiga) koridor jalur sepeda tersebut adalah Perumahan Prima HarapanStasiun Bekasi dengan Rute Jalan Raya Perjuangan yang terdiri dari 3 (tiga) segmen jalan; Perumahan Kemang Pratama-Summarecon Bekasi dengan Rute Jalan Boulevar Selatan, Jl. Boulevar Ahmad Yani, Jl. Ahmad Yani, dan Jalan Raya Pekayon; Perumahan Wisma Jaya-Stasiun Bekasi dengan rute Jalan Raya Perjuangan, Jalan Agus Salim, dan Jalan Mekarsari.

Kata Kunci :Jalur Sepeda, Rute Jalur Sepeda, Integrasi Jalur Sepeda

\section{PENDAHULUAN}

\section{Latar Belakang}

Perwujudan kota yang berwawasan lingkungan menjadi konsep untuk menyeimbangkan aktivitas pembangunan yang kian pesat. Salah satu caranya adalah dengan pemilihan sarana transportasi yang lebih ramah lingkungan, yaitu mengakomodasi kendaraan tidak bermotor. Trend saat ini gaya hidup yang ramah lingkungan di berbagai kota di Indonesia dilakukan dengan pemanfaatan sepeda sebagai alternatif untuk mendukung pergerakan masyarakat. Preferensi sarana transportasi sepeda tidak serta merta dapat diterapkan di wilayah Bekasi. Penggunaan sepeda sebagai alternatif transportasi yang ramah lingkungan berhubungan dengan penyediaan angkutan umum perkotaan. Volume kendaraan bermotor di wilayah Bekasi saat ini cukup tinggi dan didominasi oleh kendaraan pribadi. Penerapan jalur sepeda tidak akan berhasil tanpa upaya pengurangan volume kendaraan pribadi. 
Telah banyak masyarakat di wilayah Bekasi yang telah tergabung dalam komunitas bersepeda. Hal tersebut menunjukkan bahwa masyarakat sangat antusias terhadap program tersebut. Adanya komunitas sepeda merupakan embrio adanya perubahan gaya hidup masyarakat menuju kota yang berwawasan lingkungan. Dukungan lainnya adalah dari pihak pemerintah yang telah menggalakkan kegiatan pro lingkungan di wilayah Bekasi, seperti penyediaan jalur sepeda pada hari libur yang telah ditetapkan sebagai satu paket dengan kegiatan pro lingkungan seperti Car Free Day di jalan-jalan wilayah Kabupaten maupun Kota di wilayah Bekasi.

\section{METODOLOGI PENELITIAN}

Penelitian ini dilakukan di Sekolah Tinggi Transportasi Darat. Secara garis besar alur penelitian dapat dilihat pada Gambar berikut

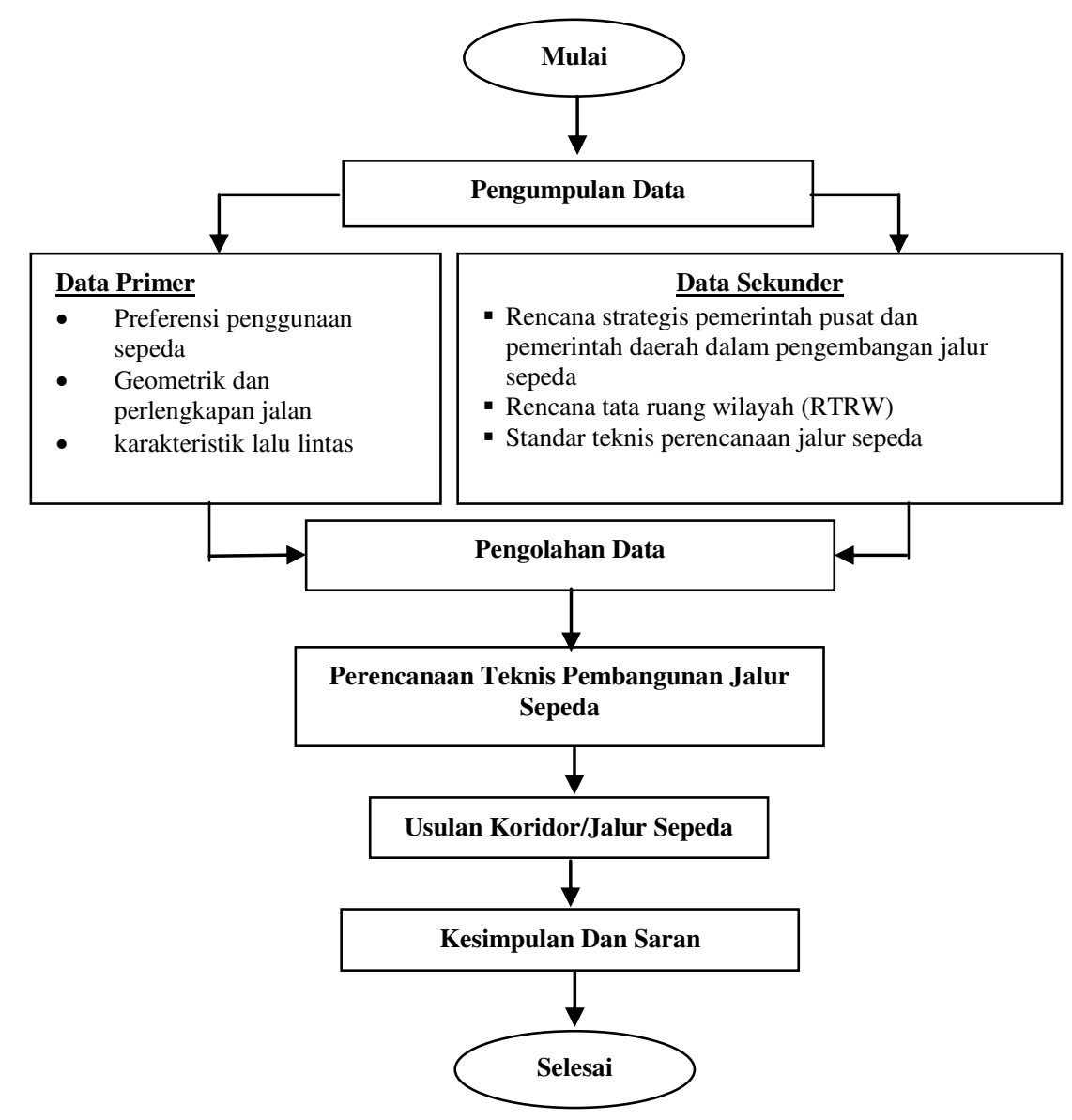

Gambar 1 Bagan Alir Penelitian 
Pada penelitian ini, pengumpulan data dibagi menjadi dua,yakni pengumpulan data sekunder dan primer.

1. Data sekunder, yang dibutuhkan untuk mendukung sebagai bahan analisis dalam penelitian ini antara lain rencana strategis pemerintah pusat dan pemerintah daerah dalam pengembangan jalursepeda, Rencana tata ruang wilayah (RTRW), Standar teknis perencanaan jalur sepeda. Data sekunder didapat dari berbagai sumber.

2. Data primer, yang dibutuhkan dalam penelitian ini antara lain:

a. Data Preferensi Penggunaan Sepeda

Data ini dapat diperoleh melalui pendekatan wawancara kepada sampel penduduk di wilayah Jabidetabek guna mengidentifikasi permintaan masyarakat terhadap penggunaan sepeda sepeda sebagai sarana transportasi alternatif dalam mendukung pergerakan orang sesuai dengan karakteristik wilayah.

b. Data Geometrik dan Perlengkapan Jalan

Data ini dapat diperoleh dengan menggunakan metode inventarisasi dengan melakukan pengamatan dan pengukuran terhadap komponen geometrik dan perlengkapan jalan guna mengetahui karakteristik jalan yang merupakan prasarana utama dari pergerakan sepeda dalam lingkup wilayah Bekasi.

c. Data Karakteristik Lalu Lintas

Data ini dapat diperoleh dengan melakukan pengamatan dan pengukuran selama periode waktu tertentu terhadap elemen dasar/primer maupun sekunder dari sistem lalu lintas. Pengumpulan data melalui pendekatan survai pencacahan lalu lintas terklasifikasi dan survai kecepatan pada jaringan jalan di wilayah Bekasi. Data ini digunakan dalam menyusun rencana rute maupun kriteria teknis kebutuhan fasilitas jalur sepeda. 


\section{ANALISIS DAN PEMBAHASAN}

\section{A. Analisis Pemilihan Rute Jalur Sepeda}

1. Karakteristik Responden

Dalam proses pemilihan rute jalur sepeda, ruas jalan dipilih berdasarkan kriteria-kriteria tertentu yang merupakan turunan dari hasil Stated Preference. Dibawah ini merupakan kriteria-kriteria yang digunakan dalam memilih rute jalur sepeda.

Tabel. Kriteria Pemilihan Rute Jalur Sepeda

\begin{tabular}{|c|c|c|c|c|}
\hline \multirow{2}{*}{ No. } & \multirow{2}{*}{ Kriteria } & \multicolumn{3}{|c|}{ Sub Kriteria } \\
\hline & & Nama Sub Kriteria & Indikator Kinerja & Keterangan \\
\hline \multirow[t]{2}{*}{1} & $\begin{array}{c}\text { Keterhubungan \& } \\
\text { Langsung / Direct } \\
\text { Connected }\end{array}$ & Jarak Terpendek & $\mathrm{km}$ & \\
\hline & & $\begin{array}{l}\text { Hambatan (U- } \\
\text { Turn) }\end{array}$ & titik & \\
\hline \multirow[t]{4}{*}{2} & Keselamatan / Safety & $\begin{array}{l}\text { Kecepatan } \\
\text { Kendaraan } \\
\text { Bermotor }\end{array}$ & $\mathrm{km} / \mathrm{jam}$ & \\
\hline & & VCR & rasio & \\
\hline & & $\begin{array}{l}\text { Lalu Lintas } \\
\text { Kendaraan Barang }\end{array}$ & $\%$ & \\
\hline & & Parkir On-Street & $\begin{array}{l}\text { Sangat } \\
\text { Rendah/Rendah/Sed } \\
\text { ang/Tinggi/Sangat } \\
\text { Tinggi }\end{array}$ & $\begin{array}{l}\text { Sangat Rendah }=0-15 \% \text { Parkir On } \\
\text { Street Setiap Segmen Ruas Jalan, } \\
\text { Rendah } 16 \%-40 \% \text {, Sedang }=41 \%- \\
60 \% \text {, Tinggi }=61 \%-85 \% \text {, Sangat } \\
\text { Tinggi }=86 \%-100 \%\end{array}$ \\
\hline \multirow[t]{4}{*}{3} & Kenyamanan / Comfort & Persimpangan Jalan & Titik & \\
\hline & & Kualitas Jalan & Baik/Sedang/Buruk & \\
\hline & & Lebar Jalan & Meter & \\
\hline & & Trotoar & Meter & \\
\hline
\end{tabular}




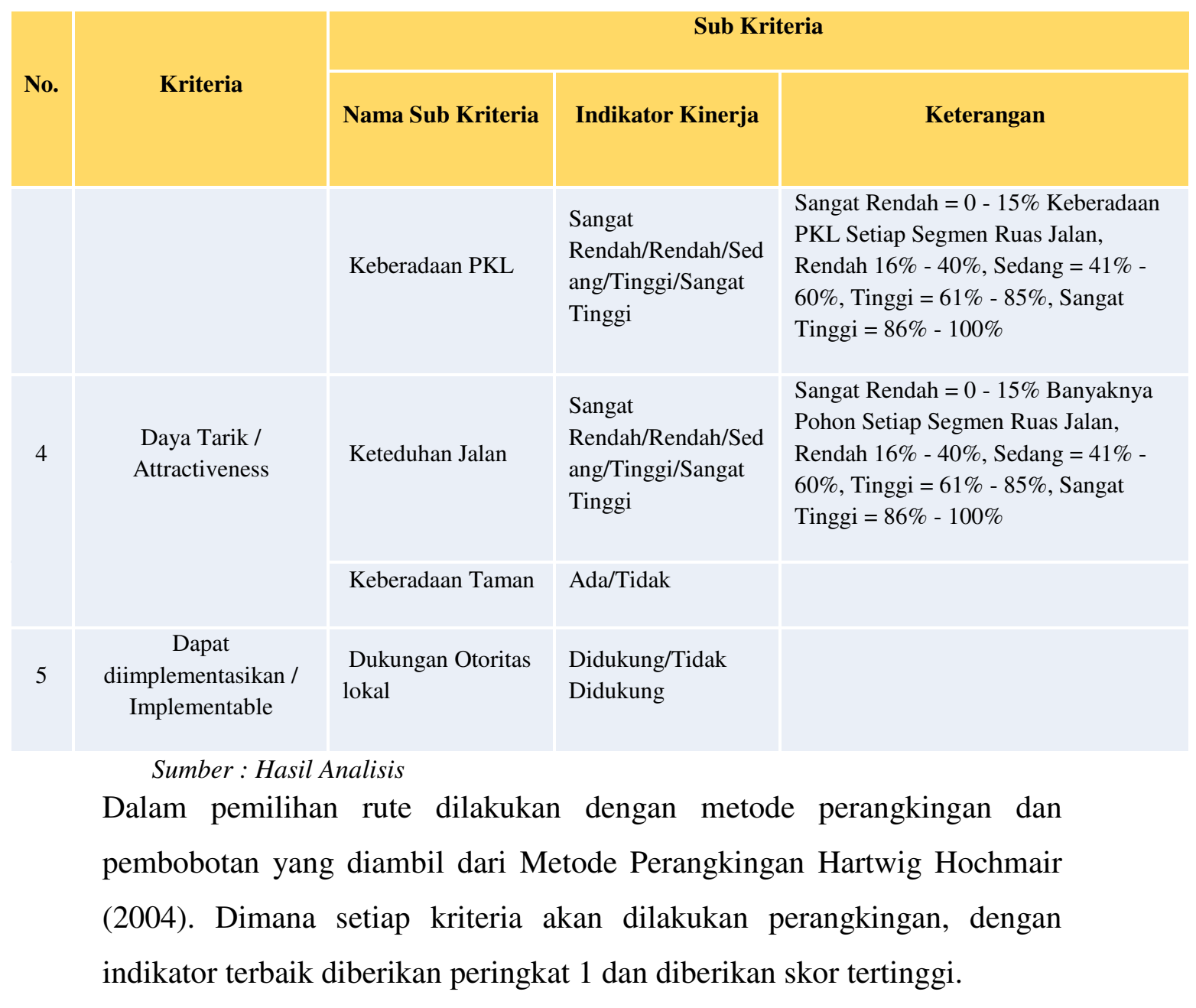

Tabel. Kriteria Tambahan

\begin{tabular}{|c|c|c|c|c|}
\hline Kriteria & Range & Penjelasan & $\begin{array}{c}\text { Skor } \\
\text { Range }\end{array}$ & Keterangan \\
\hline \multirow{5}{*}{$\begin{array}{l}\text { Keteduhan } \\
\text { Jalan, } \\
\text { Keberadaan } \\
\text { PKL, Parkir } \\
\text { On-Street }\end{array}$} & $\begin{array}{l}\text { Sangat } \\
\text { Rendah }\end{array}$ & $\begin{array}{l}0-15 \% \\
\text { Banyaknya } \\
\text { Pohon padasetiap } \\
\text { segmen ruas jalan }\end{array}$ & 10 & \multirow[t]{5}{*}{$\begin{array}{l}\text { Dilakukan } \\
\text { Perangkingan }\end{array}$} \\
\hline & Rendah & $16 \%-40 \%$ & 30 & \\
\hline & Sedang & $41 \%-60 \%$ & 50 & \\
\hline & Tinggi & $61 \%-85 \%$ & 70 & \\
\hline & Sangat Tinggi & $86 \%-100 \%$ & 90 & \\
\hline \multirow[t]{3}{*}{ Kualitas Jalan } & Rendah & $\begin{array}{l}\text { 41-100\% Kondisi } \\
\text { Jalan Rusak }\end{array}$ & 80 & \multirow[t]{3}{*}{$\begin{array}{l}\text { Dilakukan } \\
\text { Perangkingan }\end{array}$} \\
\hline & Sedang & $11-40 \%$ & 50 & \\
\hline & Baik & $0-10 \%$ & 30 & \\
\hline
\end{tabular}

Sumber : Hasil Analisis 
Berdasarkan hasil analisis diperoleh hasil bahwa terdapat 3 Koridor pengembangan jalur sepeda yaitu :

1. Kawasan Pemukiman Perumahan Prima Harapan - Stasiun Bekasi

- Rute 1 : Jln. Ir. H. Juanda - Jln. A. Yani - Jln. Bulevar A. Yani Jln. Bulevar Selatan - Jln. Raya Perjuangan 3

- Rute 2 : Jln. Raya Perjuangan 1 - Jln. Raya Perjuangan 2 - Jln. Raya Perjuangan 3

2. Kawasan Pemukiman Perumahan Kemang Pratama - Summarecon Bekasi

- Rute 1 :Jln. Boulevar Selatan - Jln. Boulevar A. Yani - Jln. A. Yani - Jln. Raya Pekayon

- Rute2 :Jln. Ir. H. Juanda - Jln. Kemakmuran - Jln. Veteran - Jln. Mayor Hasibuan - Jln. A. Yani - Jln. Raya Pekayon

3. Kawasan Pemukiman Perumahan Wisma Jaya - Stasiun Bekasi

- Rute 1 :Jln. Raya Perjuangan 1 - Jln. Baru Perjuangan - Jln. Agus Salim 2 - Jln. Mekarsari - Jln. Agus Salim 3

- Rute2 :Jln. Ir. H. Juanda - Jln. Agus Salim 1 - Jln. Agus Salim 2 Jln. Mekarsari - Jln. Agus Salim 3

\section{B. Analisis Tipikal Jalur Sepeda}

Penentuan tipikal jalur sepeda merupakan salah satu tujuan dari dokumen perencanaan teknis ini yang mengacu pada literatur Mulyadi, 2013 yang menguraikan tipe/jenis jalur sepeda berdasarkan fungsi jalan yaitu sebagai berikut.

Tabel. Pemilihan Jalur Sepeda di Badan Jalan, Jalur Sepeda di Trotoar dan Lajur Sepeda di Badan Jalan Berdasarkan Fungsi dan Kelas Jalan di Perkotaan 


\begin{tabular}{lccc}
\hline & Jalan Raya & Jalan Sedang & Jalan Kecil \\
\hline Arteri primer & $\mathrm{A}$ & $\mathrm{A}$ & $\mathrm{A}$ \\
Kolektor primer & $\mathrm{A}$ & $\mathrm{A}$ & $\mathrm{A}$ \\
Lokal primer & $\mathrm{C}$ & $\mathrm{C}$ & $\mathrm{C}$ \\
Lingkungan primer & $\mathrm{C}$ & $\mathrm{C}$ & $\mathrm{C}$ \\
Arteri sekunder & $\mathrm{A} / \mathrm{B}$ & $\mathrm{A} / \mathrm{B}$ & $\mathrm{A} / \mathrm{B}$ \\
Kolektor sekunder & $\mathrm{B} / \mathrm{C}$ & $\mathrm{B} / \mathrm{C}$ & $\mathrm{B} / \mathrm{C}$ \\
Lokal sekunder & $\mathrm{B} / \mathrm{C}$ & $\mathrm{B} / \mathrm{C}$ & $\mathrm{B} / \mathrm{C}$ \\
Lingkungan sekunder & $\mathrm{B} / \mathrm{C}$ & $\mathrm{B} / \mathrm{C}$ & $\mathrm{B} / \mathrm{C}$ \\
\hline Sumber: Mulyadi, $20 / 3$ & & &
\end{tabular}

Keterangan:

A : Tipe jalur sepeda di badan jalan

B : Tipe lajur sepeda di trotoar

C : Tipe lajur sepeda di badan jalan

Berdasarkan tabel tersebut diuraikan bahwa tipe jalur sepeda dibagi menjadi 3 (tiga) tipe yaitu Tipe A (tipe jalur sepeda di badan jalan), Tipe B (tipe lajur sepeda di trotoar), Tipe C (tipe lajur sepeda di badan jalan). Ketiga tipe jalur sepeda tersebut dilengkapi dengan rambu dan marka petunjuk jalur sepeda guna menjamin keamanan dan keselamatan pengguna sepeda dalam berlalu lintas di jalan.

Dibawah ini merupakan rekomendasi Tipikal Jalur Sepeda pada rute terpilih :

Tabel. Tipikal Jalur Sepeda

\begin{tabular}{|c|c|c|}
\hline No. & Nama Ruas Jalan & Tipikal \\
\hline \multicolumn{2}{|c|}{ Kawasan Pemukiman Perumahan Prima Harapan - Stasiun Bekasi } \\
\hline 1 & Jln. Raya Perjuangan 1 & "B/C" \\
\hline 2 & Jln. Raya Perjuangan 2 & "B/C" \\
\hline 3 & Jln. Raya Perjuangan 3 & "B/C" \\
\hline Kawasan Pemukiman Perumahan Kemang Pratama - Summarecon Bekasi \\
\hline 4 & Jln. Boulevar Selatan & "B/C" \\
\hline 5 & Jln. Boulevar A. Yani & "A/B" \\
\hline 6 & Jln. A. Yani & "B/C" \\
\hline 7 & Jln. Raya Pekayon & "B \\
\hline \multicolumn{3}{|l|}{ Kawasan Pemukiman Perumahan Wisma Jaya - Stasiun Bekasi } \\
\hline
\end{tabular}




\begin{tabular}{|c|l|c|}
\hline 8 & Jln. Raya Perjuangan 1 & "B/C" \\
\hline 9 & Jln. Baru Perjuangan & "B/C" \\
\hline 10 & Jln. Agus Salim 2 & "B/C" \\
\hline 11 & Jln. Mekarsari & "B/C" \\
\hline 12 & Jln. Agus Salim 3 & "B/C" \\
\hline
\end{tabular}

Sumber : Hasil Analisis

\section{Peta Rute Jalur Sepeda}

Peta rute jalur sepeda lebih diutamakanaspek konektifitas dan terintegrasi

Dibawah ini akan merupakan Peta Rute Jalur Sepeda pada Kawasan Pemukiman Perumahan Prima Harapan - Stasiun Bekasi.

\section{KESIMPULAN DAN SARAN}

\section{A. Kesimpulan}

Setelah melakukan penelitian mengenai penelitian Perencanaan Jalur Sepeda yang Terintegrasi di Kota Bekasi, maka dapat ditarik kesimpulan yaitu:

1. Terdapat 3 (tiga) koridor jalur sepeda yang direkomendasikan di Kota Bekasi dengan konsep keterhubungan antar bangkitan perjalanan dalam hal ini area pemukiman dengan area tarikan perjalanan yaitu simpul transportasi stasiun kereta maupun area komersil. 3 (tiga) koridor jalur sepeda tersebut adalah :

- Perumahan Prima Harapan-Stasiun Bekasi dengan Rute Jalan Raya Perjuangan yang terdiri dari 3 (tiga) segmen jalan.

- Perumahan Kemang Pratama-Summarecon Bekasi dengan Rute Jalan Boulevar Selatan, Jl. Boulevar Ahmad Yani, Jl. Ahmad Yani, dan Jalan Raya Pekayon.

- Perumahan Wisma Jaya-Stasiun Bekasi dengan rute Jalan Raya Perjuangan, Jalan Agus Salim, dan Jalan Mekarsari.

2. Penentuan tipikal jalur sepeda di koridor yang telah ditentukan adalah sebagai berikut.

- Koridor Perumahan Prima Harapan-Stasiun Bekasi degan Tipikal jalur sepeda tipe "B/C" 
- Koridor Perumahan Kemang Pratama-Summarecon Bekasi dengan Tipikal jalur sepeda tipe "B/C" pada ruas jalan Boulevar Selatan dan Ruas jalan Raya Pekayon serta tipe “A/B” pada ruas jalan Boulevar Ahmad Yani dan jalan A. Yani.

- Koridor Perumahan Wisma Jaya -Stasiun Bekasi degan Tipikal jalur sepeda tipe "B/C"

\section{B. Saran}

Setelah melakukan penelitian mengenai Perencanaan Jalur Sepeda yang Terintegrasi di Kota Bekasimaka disarankan :

1. Penerapan jalur sepeda harus dilakukan secara terkordinasi antar kepentingan mulai dari unsur pemerintah, swasta sebagai pengelola, serta kesadaran masyarakat sebagai pengguna sistem transportasi yang ramah lingkungan.

2. Perlu dilakukan upaya-upaya pengembangan infastruktur sistem transportasi yang ramah lingkungan untuk meningkatkan kesadaran masyarakat menggunakan moda alternatif tersebut.

\section{DAFTAR PUSTAKA}

2009. Undang-Undang Republik Indonesia Nomor 22 Tahun 2009. Tentang Lalu Lintas dan Angkutan Jalan.

.Undang-Undang Republik Indonesia Nomor 38 Tahun 2004 Tentang Jalan.

.Undang-Undang Republik Indonesia Nomor 32 Tahun 2004. Tentang Pemerintahan Daerah.

.Undang-Undang Republik Indonesia Nomor 12 Tahun 2011. Tentang Pembentukan Peraturan Perundang-undangan.

.Peraturan Pemerintah =Republik Indonesia Nomor 32 Tahun 2011 Tentang Manajemen dan Rekayasa, Analisis Dampak dan Manajemen Kebutuhan Lalu Lintas. 
.Peraturan Pemerintah Nomor Republik Indonesia Nomor 34 Tahun 2006 Tentang Jalan

BPS. 2017. Kota Bekasi dalam Angka

.1997, Manual Kapasitas Jalan Indonesia (MKJI), Direktorat Jenderal Bina Marga, Jakarta

Khisty, C. Jotin \& Lall, B. Kent, 2005, Dasar-dasar Rekayasa Transportasi, Jakarta

Munawar, Achmad, 2006, Manajemen Lalu Lintas Perkotaan, Jogjakarta

Sukirman, S, 1999, Dasar-dasar Perencanaan Geometrik Jalan, Nova, Bandung

Duren, Kreis, 2011, Radandern im Kreis Duren, Bremerhaven Gemrny

Artiningsih,dkk, 2011, Kajian Peluang Penerapan Jalur Sepeda di Kota Semarang, PLTR, Universitas Diponegoro Semarang 